\title{
Inbreeding depression on reproductive performance and survival in captive gazelles of great conservation value
}

\author{
Jorge Cassinello \\ Instituto de Investigación en Recursos Cinegéticos, IREC \\ (CSIC, UCLM, JCCM), \\ Ronda de Toledo s/n, 13005 Ciudad Real, Spain
}

Address for correspondance:

Dr. Jorge Cassinello

Instituto de Investigación en Recursos Cinegéticos, IREC

(CSIC, UCLM, JCCM)

Ronda de Toledo s/n, 13005 Ciudad Real, Spain

E-mail: jorge.cassinello@uclm.es 


\section{Abstract}

Here I present a detailed analysis of individual inbreeding coefficient effects on some reproductive parameters and longevity in three species of gazelles under different conservation status: vulnerable dorcas gazelle, endangered Cuvier's gazelle, and extinct in the wild mhorr gazelle. The novelty of this study stems from the inclusion of both males and females in analyses including a large database of information collected during two decades of periodical studbook inventories for these species. Translocations to different zoo locations of the extinct subspecies mhorr gazelle do not apparently affect reproductive performance (population sex ratio) or individual longevity. In agreement with previous works, the average inbreeding coefficients vary inter-specifically, being higher in Cuvier's, followed by mhorr and dorcas gazelles. This reflects the different population size of the founding individuals of each species' captive population. Sexual maturity and age at first birth follow an allometric pattern, occurring at an earlier age in the smallest species (dorcas), followed by Cuvier's and then the mhorr gazelle. Twinning in Cuvier's gazelle depends on maternal experience, as it is less frequent in primiparous females. Inbreeding affects neither twinning nor sex ratio. Mhorr gazelles' studbook shows several causes of death and it emerges that a higher proportion of non-inbred females die due to pathologies than males, although both sexes show similar proportion of mortal pathologies when inbred. Multifactor ANOVA shows that longevity decreases with inbreeding level and that females live longer than males in the three species of gazelles studied, as expected in polygynous mammals. Mhorr and dorcas non-inbred females show higher juvenile survival than males, whereas inbred individuals show a similar declining juvenile survival, particularly in mhorr and Cuvier's gazelles. Finally, it is discussed the apparent 
inbreeding tolerance in Cuvier's species, and the great value keeping and studying long term data of well-monitored captive populations may prove to the conservation of threatened species.

Key-words: captive populations, inbreeding depression, longevity, sexual maturity, ungulates.

\section{Introduction}

Zoological institutions make huge efforts in keeping and breeding endangered species, with a view to preserve them from extinction and, ideally, to reintroduce them back in their natural habitats (Cade, 1988; Rahbeck, 1993; Snyder et al., 1996; Komers and Curman, 2000). One of the main problems that captive breeding programs have to face is the denominated founder effect, i.e., deleterious effects on the captive population derived from few founder individuals and the consequent loss of genetic diversity (see Gompper et al., 1997). Population genetic theory predicts that, in the absence of mutation and migration, small, isolated (captive) populations will lose variation over time as a result of their limited size, loss rate depending on the effective population size $\left(\mathrm{N}_{\mathrm{e}}\right)$ and the number of generations the population is isolated (Frankel \& Soulé, 1981; Frankham, 1995a). Therefore, institutions that undergo captive-breeding programs try to maximize population heterozygosity by carefully selecting breeding individuals according to their genetic variability, so that the presence of individuals homozygous for deleterious alleles is minimized (Foose and Ballou, 1988). 
Inbreeding depression is the decline in the value of a trait as a consequence of inbreeding (Wright, 1977). Traits more commonly considered are those related to individual fitness, such as reproductive parameters or survival rate. Principally in captivity, there is a fairly large amount of research showing that inbreeding reduces fitness in animal populations (e.g., Ballou and Ralls, 1982; Charlesworth and Charlesworth 1987; Thornhill 1993). It has not been until recently, however, that studies carried out in the wild have shown a relationship between inbreeding and fitness (e.g. van Noordwijk and Scharloo 1981; Keller 1998; Slate et al., 2000; see revision in Keller and Waller, 2002), and even an increase of extinction risk (Saccheri et al., 1998; Brook et al., 2002; Reed et al., 2003). Now we might put to rest the hot debate on genetic variability and its relationship to wild populations viability (e.g. Mills and Smouse 1994; Frankham 1995b,c). Indeed it has been postulated that inbreeding depression may be higher under stressful and harsh conditions in the wild (Crnokrak and Roff, 1999; Reed et al., 2002).

In order to undergo a proper management and detailed analyses on the effects of genetic variability on individual fitness, knowledge of the inbreeding coefficient $F$ (Ballou, 1983) is essential (see Falconer and MacKay, 1996). Empirical evidence has shown that one of the main deleterious effects of high inbreeding coefficients is the reduction of adults fertility and offspring survival (e.g., Ralls et al. 1979; Ballou and Ralls, 1982; Hass, 1989; Stockley et al., 1993), in some ungulate species through the decrease of birth weight (e.g. MacNeil et al. 1989; Alados and Escós, 1991; Cassinello, 1997). 
Here long-term data on captive populations of dorcas gazelle (Gazella dorcas neglecta Lavauden 1926), Cuvier's gazelle (Gazella cuvieri Ogilby 1841) and mhorr gazelle (Gazella dama mhorr Bennet 1833) living at the Estación Experimental de Zonas Áridas (EEZA), in Almería (Spain), were analysed from their published studbook files (Cano, 1991; Abaigar, 1993; Escós, 1992, respectively). Gazella dorcas is considered as Vulnerable (A1a), and Cuvier's gazelle Endangered (C2a) (IUCN, 2002). Mhorr gazelles are believed to be extinct in the wild since 1968, and only exists as captive/reintroduced populations (Abaigar et al., 1997; Cassinello and Pieters, 2000), whereas the species, Gazella dama, is categorized as Endangered (A1c, C1) by the IUCN (2002). Unfortunately, to the best of my knowledge, no information is available from wild populations of the study species, nor from other captive ones, that might allow inter-population comparative analyses, as well as, defining life-history traits in the wild.

Even though the three study gazelle populations have already been subject to a series of studies, including, e.g., factors determining reproductive success in females (Alados and Escós, 1991), effects of inbreeding on ejaculate traits (Cassinello et al., 1998; Gomendio et al., 2000) and sex ratio variation in Cuvier's females (Alados and Escós, 1994), because only a small fraction of these populations has been included, to date, the power of the statistical tests carried out is likely to be low. The objective of this study is to analyse in detail the relationship between individual inbreeding coefficient and some key reproductive parameters as well as longevity, using the most complete database available from published sources, which corresponds to the whole captive populations of the study species at the time of publication (see below). 


\section{Material and Methods}

\section{The study populations}

The study population contains all individuals born at the EEZA according to their published studbooks (Cano, 1991; Escós, 1992; Abaigar, 1993) plus others obtained from EEZA staff: 383:369 dorcas, 207:206 Cuvier's and 253:254 mhorr gazelles. The founder population of each species consisted in 11:13 dorcas, 3:9 mhorr and 2:2

Cuvier's gazelles, which has led to quite dissimilar average inbreeding coefficients between them due to differing effective population sizes (see Results).

Animals of the three species are kept in four different types of enclosures, mediated by their innate territorial behaviour:

1) All-male groups. They are single, with no mating experience. Usually made up of no more than 5 individuals, except dorcas gazelle, which may be kept as relatively large groups due to their small size.

2) Reproductive groups. Made up of females with infants and an adult male.

3) Isolated males. Males who have been kept in reproductive groups are usually placed isolated afterwards, because they tend to be too aggressive if kept with other single males. Also, if a non-experienced male is potentially valuable to be used as a reproductive male, he is usually kept alone, in order to prevent fatal accidents with other males. Two one-male cages of the same species are never placed contiguously, to prevent expected agonistic behaviours.

4) All-female groups with infants. Formerly reproductive groups from which, to control population growth, the adult male has been removed. 
Young males are usually removed from their familiar groups when they reach juvenile status to prevent them mating with females; although relatively young males occasionally court and mate with adult females. Females mate for the first time at various ages, depending upon herd composition, but their sexual maturity age can easily be assessed. These events can be obtained from the species studbook files and allowed me to establish sexual maturity age in the three species.

The mhorr gazelle population

A more detailed analysis could be carried out in mhorr gazelles, as individuals' cause of death and translocations to different zoo locations are indicated in the species published studbook (Cano, 1991). Up to eight different causes of death can be distinguished in mhorr gazelle population:

1) Pathology: death caused by a pathology or illness.

2) Traumatism: death caused by a severe blow or hit against the enclosure fences, in some cases originated by capture attempts.

3) Non-nursed: the infant is abandoned by his/her mother after birth.

4) Born dead.

5) Herdmate aggression: death caused by severe injuries produced by herdmates.

6) Sacrified: at the EEZA, when very old individuals show chronic illness, they are usually sacrified to prevent them from suffering.

7) Motherless: mother's infant dies while he/she is still a few hours/days old.

8) Post-partum death: mother's death after parturition, which is irremediably followed by her infant's death due to cause 4 or 7 . 
At the time the mhorr gazelle studbook was published (Cano, 1991), this subspecies was breeding in several zoo institutions, in Spain (EEZA, Icona in Almería, and Córdoba Zoo), Germany (Frankfurt Zoo, Berlin Tierpark, Quarantine Station in Bremen, and Zoo Osnabrück), USA (San Diego Zoo, San Diego Wild Animal Park, Palm Desert Living Reserve in San Diego, Earl Tatum Holliday Island in San Diego, and Miami Zoo), and Senegal (Gueumbeul Special Fauna Reserve in St. Louis). For every mhorr gazelle its birth place and death place were known, that is, whether it had been translocated or moved from one zoo park to another. For statistical comparisons I considered country divisions as factor levels, due to their climatic/geographical differences: Spain, Germany, USA and Senegal.

\section{Inbreeding coefficients}

Inbreeding coefficients were exclusively obtained from studbook data, so that in the analyses the founding individuals, which were captured in the wild, were considered as non-inbred. Therefore, the succeeding results do not account for possible differences that may have been experienced by the founding individuals in their natural populations.

Fatherhood could be readily established for any individual born at the EEZA, as only one reproductive male was present with the female herds at a time. This allowed the reconstruction of whole pedigrees, and the calculation of individual coefficients of inbreeding $(F)$ following the Additive Relationship Method (Wright, 1922; Ballou, 1983), by means of FSpeed software package (Tenset Technologies Ltd). Purely non- 
inbred individuals $(F=0)$ were included in analyses meant to establish parameters of individuals not depressed by consanguineous matings. Also, for certain tests, two inbreeding classes were distinguished: non-inbred individuals $(F=0)$ vs inbred ones $(F>0)$. When taking into consideration individuals' longevity, however, there were too few non-inbred Cuvier's gazelles, so that I composed two classes of individuals determined by the median of the distribution for each species (see Table 1). This variable is denominated median-inbreeding and has two possible values: below or above the median of the population inbreeding coefficient, termed low-inbred and high-inbred, respectively. Those individuals retaining exactly the median inbreeding coefficient were assigned to either low or high-inbred group depending on the size of both groups, while trying to attain similar group sizes. This classification will allow to use inbreeding as a more effective two-valued factor variable in the ANOVA, by achieving equal sample sizes and, therefore, reinforcing the power of the statistical test (see Zar, 1984: 164).

\section{Statistics}

Statistical analyses were two-tailed and at a 0.05 level of significance. Throughout the study, when parametric tests were used non-normal dependent variables were transformed to conform to normality (see, e.g., Zar, 1984). In the Analysis of Variance tests (ANOVAs), significance of factors with more than two levels was assessed by the Games-Howell post-hoc test, as in all cases variances and group size were unequal (Kromrey and La Rocca, 1995). Logistic Regression Analyses were carried out for response variables either nominal or ordinal. When using Contingency two-way table tests, the Fisher's exact test was applied whenever all frequencies were 
not large enough for a $\chi^{2}$ analysis (see Zar 1984). Bonferroni correction was applied whenever a single hypothesis of no effect was tested using more than one test (Perneger, 1998). The statistical package used was StatView 5.0 (SAS Institute Inc.) for Macintosh computers.

\section{Results}

\section{Zoo translocations in mhorr gazelles}

Because mhorr gazelle zoo translocations were quite frequent, I analysed whether they might interfere in any reproductive variable, before carrying out any further analyses.

Sex ratio at birth did not differ significantly from 1:1 in any of the zoological parks where the species has been breeding. Individuals' longevity was neither affected by zoo location where they died (Spain, Germany, USA and Senegal: One-way ANOVA, with country as factor: $F_{3,332}=0.45, p=0.71$ ), nor by zoo translocations (birth place different from death place), as shown by an analysis of sexually matured individuals (One-way ANOVA: $F_{1,122}=0.78, p=0.38$ ). The proportion of individuals reaching one month of age and sexual maturity was not affected by zoo location either. I can conclude that zoo location does not significantly affect the parameters and analyses that follow on mhorr gazelle.

\section{Founding population size and inbreeding coefficients}


Table 1 shows some parameters regarding founding population size, as well as inbreeding coefficients of captive populations of three gazelle species. Average inbreeding differed between them (One-way ANOVA: $F_{2,1677}=236.41, p<0.0001$; Games-Howell post hoc test confirmed statistically signficant differences between all the groups).

\section{Table 1 around here}

\section{Parturition and maternal experience}

Some reproductive traits are shown in Table 2 for the three gazelle species. Average age at first birth is practically identical in Cuvier's and mhorr gazelles, differences arising between the latter and dorcas gazelles (One-way ANOVA: $F_{2,298}=3.33, p=0.04$; Games-Howell post hoc test confirmed statistically significant differences between dorcas and mhorr females). Only Cuvier's gazelles deliver twins, at a quite high proportion (1 out of 1.4 births) compared with other ungulates (see, e.g., Cassinello and Alados, 1996). Twin birth rate depends on maternal experience, as primiparous females produce twins at a significantly lower rate (see Table 3); inbreeding has no effect, though, on this rate (Logistic Likelihood Ratio Tests: $d f=1$, Inbreeding Coefficient $\chi^{2}=1.69, p=0.19$, Maternal Experience $\left.\chi^{2}=8.01, p=0.005\right)$. No relationship was found with inbreeding and maternal experience with either offspring sex or the type of parturition (male, female, male/male, male/female, female/female). Contingency two-way table analyses allowed further explanation of differences in the proportion of the different types of parturitions according to the maternal experience; 
primiparous females significantly produced more single births than twins (Two-way table analysis: $d f=1, \chi^{2}=4.78, p=0.03$ ) whereas multiparous ones delivered a similar frequency of singles and twins in the study population (Two-way table analysis: $d f=1$, $\chi^{2}=0.45, p=0.50$ ). Both primiparous and multiparous females showed similar proportions of twin types, except for male/female birth rate which was more frequent in multiparous ones (Two-way table analysis: $d f=1, \chi^{2}=5.05, p=0.02$; see Figure 1). Sex ratio at birth is practically 1:1 in the other two species (see Table 3). No relationship was found between sex ratio and inbreeding coefficient in any of the three study species.

Table 2 around here

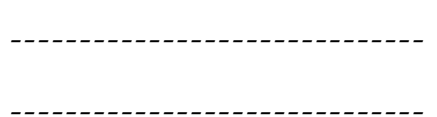

Figure 1 around here

Table 3 around here

Average inbreeding coefficients of males and females of the study population did not differ both in mhorr gazelles $(0.121 \pm 0.006(n=253)$ vs $0.107 \pm 0.006(n=254) ; t$ test: $d f=505, t=1.67, p=0.09)$ and dorcas gazelles $(0.050 \pm 0.004(n=382)$ vs $0.052 \pm 0.005$ $(n=370)$; $t$ test: $d f=750, t=-0.37, p=0.71)$, but did in the Cuvier's study population where males showed higher values than females $(0.179 \pm 0.006(n=207)$ vs $0.154 \pm 0.006(n=206) ; t$ test: $d f=411, t=2.77, p=0.01)$. This was not simply an effect due to mother's age ( $t$ test: $d f=307, t=1.10, p=0.27$ ), even though older females in all 
the study populations showed lower levels of inbreeding (Spearman Rank Correlations: Cuvier's $r h o=-0.22, p<0.0001$, mhorr $r h o=-0.23, p<0.0001$, dorcas $r h o=-0.28, p<0.0001)$.

\section{Longevity in the three gazelle species}

In order to have an initial estimate of longevity in the three study species, I calculated average longevity for non-inbred males and females (see Table 4). A two-factor ANOVA for the dependent variable longevity (transformed into its logarithmic to conform to normality) and the factors sex and species was then carried out. Cuvier's study population was not analyzed because of its small sample size. The analysis indicated no differences between dorcas and mhorr gazelles, whereas females exhibited higher longevity than males in both species $\left(\operatorname{Sex} F_{1,368}=7.84, \mathrm{p}=0.005\right.$; Species $F_{1,368}=3.94, \mathrm{p}=0.05 ;$ Sex-Species $F_{1,368}=1.33, \mathrm{p}=0.25$; significance established by Games-Howell post hoc test).

Table 4 around here

The percentage of non-inbred males and females that reached one month survival age and sexual maturity age in the three species were statistically significant different between sexes in mhorr and dorcas gazelles, as a higher proportion of females reach sexual maturity than males (Table 5). 
More non-inbred mhorr gazelle females died as a consequence of pathologies than did males. Pathology was the main cause of death in females, whereas males, by contrast, presented no statistical differences between causes of death (see Table 6).

Table 6 around here

\section{Inbreeding effects on longevity}

A simple regression analysis of longevity as a continuous variable, Bonferroni correction applied, shows that only in female gazelles is longevity negatively associated with inbreeding coefficient (Figure $2 b, d, f)$. There is a similar trend in males of the three species, but not statistically significant (Figure 2a,c,e). However, mother's inbreeding coefficient showed a significant negative relationship with sons' and daughters' longevity in mhorr gazelle $\left(n=176, R^{2}=0.10, p<0.0001 ; n=156\right.$, $R^{2}=0.08, p=0.0003$, respectively).

Figure 2 around here in the form:

$\begin{array}{cc}2 a & 2 b \\ 2 c & 2 d \\ 2 e & 2 f\end{array}$


An ANOVA was carried out considering as factors species, sex and inbreeding coefficient, the latter grouped by the median of each population (see Table 1) in order to keep group sizes unequality reduced to a minimum (see Methods). No significant differences were obtained between species longevity, but females lived longer than males and high-inbred individuals exhibited lower longevity (see Table 7).

\section{Table 7 around here}

Table 5 shows the proportion of non-inbred and inbred males and females that reached one month of age and/or sexual maturity. Sexual maturity survival differences between males and females have already been seen in dorcas and mhorr gazelles (see above). With regard to inbreeding group, the proportion of inbred Cuvier's males and inbred mhorr females that reached one month of age is lower than that of non-inbred ones; also, sexual maturity survival decreased in inbred Cuvier's males and females as well as inbred mhorr females. Dorcas individuals do not show significant survival variations.

A higher proportion of inbred mhorr gazelle males died due to pathologies than did non-inbred males, with pathology as the main cause of death; females also suffered mainly from pathologies (Table 6). I then pooled some of the death causes in order to create three straightforward classes: death caused by natural sources (including pathologies, non-nursed infants, born dead infants, herdmate aggressions, and postpartum deaths), accidents (traumatism), and sacrifices. Motherless infants were not associated with any of these classes. As commented in the Methods, at the EEZA, 
very old individuals that show evident signs of chronic illness and incapacity are sacrified. Thus death caused by sacrifice occurred only in relatively old individuals (4.99 \pm 1.00 years) whereas the average age of individuals dead due to natural reasons $(1.73 \pm 0.23$ years $)$ and to accidental collisions $(1.14 \pm 0.15$ years $)$ was significantly lower (ANOVA: $F_{2,296}=11.01, p<0.0001$, Games/Howell test significant between sacrifice and natural and accidental death). A higher proportion of inbred mhorr gazelles ( $n=169)$ died due to natural deaths and accidents than non-inbred ones (58) (Contingency two-table test for natural deaths: $d f=1, \chi^{2}=28.92, \mathrm{p}<0.0001$;

Contingency two-table test for accidents: $d f=1, \chi^{2}=5.86, p=0.01$ ).

\section{Discussion}

Inbreeding effects on reproductive traits and longevity is analysed in captive populations of three gazelle species under different degree of conservation according to the IUCN, (IUCN, 2002). Effective population sizes of the founding populations of the study gazelle species are small, but sex ratios of founding individuals are very close to 1:1 in dorcas and Cuvier's gazelles (11:13 and 2:2, respectively). The sex ratio of 3:9 for founding mhorr gazelles is actually closer to a natural sex ratio in breeding groups for polygynous species (see Frankel \& Soulé, 1981: 38). Of the three study species, Cuvier's gazelle is the one with the smaller founding population size and higher heterozygosity loss per generation (13\%, see Table 1$)$. This leads to a significantly higher average inbreeding coefficient. 
Inbred individuals show lower survival rate than non-inbred ones, the effects being sex-dependent. No relevant relationships were found between inbreeding and parturitions and sex ratio.

The translocation of animals between sites is a common practice in the conservation management of wild populations (Griffith et al., 1989), including both wildlife reserves or parks and captive-breeding institutions. Translocations may work as reintroduction programmes in the wild (Bright and Morris, 1994), or, when carried out between zoos, to reduce inbreeding (Gompper, 1997) and, in cases of seriously endangered species, to avoid the existence of isolated captive populations which may be prone to hazardous risks, such as infections or fatal diseases. Unfortunately, most translocations in the wild have been conducted without ulterior monitoring (e.g. Watson et al. 1992; Cano et al., 1993) with a few exceptions (e.g. Kleiman et al., 1986; Stanley Price, 1989; Carbyn et al., 1994). Previous studies on mortality rate in captive mammals have reported significant differences between institutions, suggesting that differences in management practices may be largely responsible for these observed changes (e.g., Wielebnowski, 1996). Mhorr gazelles have been transferred to different captive-breeding centres located in Europe, America and Africa. Although the zoological facilities were situated in four different countries (Spain, Germany, USA and Senegal) there were no differences in adult longevity and one month of age longevity between them, even though these facilities differed in their management regime: captive zoo institutions vs wildlife reserves (see the Study Populations in the Methods). More recently, the subspecies has been introduced in Bou-Hedma National Park (Tunisia) and monitored since then (Abaigar et al., 1997). 
Some elemental reproductive traits are analysed for the three study species. Average age at first birth in captivity is quite similar between them, coming out significant differences between dorcas and mhorr (cf. Alados and Escós, 1991); but this result is mediated by captive conditions, as groups/herds composition and female-female competition when accessing to resources, including mating, may interfere in the reproductive performance, particularly that of young females (e.g. Harcourt, 1987). Types of parturitions (single and twins births) as well as maternal experience are directly related to females reproductive success (Clutton-Brock, 1988) and may depend on maternal condition (Alados and Escós, 1994; Cassinello and Gomendio, 1996), which, in turn, may be affected by inbreeding (e.g., Ryder, 1987; Alados and Escós, 1991). However, no significant results were obtained between these variables and inbreeding, which seems to indicate that deleterious effects caused by the latter are not translated into individuals' reproductive performance in these species.

The results obtained show that non-inbred females live longer than males in dorcas and mhorr gazelles, a higher proportion of females than males reaching one month of age and sexual maturity. These sexual differences in life expectancies are consistent with the postulated cost associated with sexual dimorphism in polygynous mammals (Promislow, 1992), particularly under good environmental conditions (Tö̈go \& Gaillard, 2003), as it might be the case of the study population, where food is provided ad libitum. The lack of any statistical difference in Cuvier's gazelle might be caused by the small sample size of non-inbred individuals held at the EEZA. In fact, a multifactor ANOVA shows that sex and inbreeding are the independent variables explaining longevity variance in the study populations, females living longer than 
males, and low-inbred individuals longer than high-inbred ones (see, e.g., Brown and Brown, 1998; Keller, 1998; Grant et al., 2001).

An analysis of longevity as a function of inbreeding (Figure 2) showed statistically significant negative associations for females of all three study species. In males, a negative but not significant tendency was observed. Alados and Escós (1991), using a subset of the same populations, observed the same negative association between inbreeding and longevity in females of Cuvier's and mhorr gazelles. The low $\mathrm{R}^{2}$ values obtained in the significant regression analyses (see Figure 2) might be explained by the expected relationship between longevity and body condition, a variable not included in this study (see, e.g., Cassinello \& Alados, 1996). The lack of a statistically significant relationship between inbreeding and longevity in males might be explained either by a small sample size or more probably by the already low longevity rate observed in non-inbred males compared with that of females (see Table 5), so that inbred individuals do not show such an acute decrease in longevity. However, an analysis of maternal inbreeding demonstrated a significant negative relationship between longevity and inbreeding in mhorr males, as seen in other species (Lacy et al., 1996; Ballou, 1997).

Concerning causes of death in mhorr gazelles, it is notable that non-inbred females died mostly due to pathologies, which was the main cause of death both in inbred males and females. An explanation for this may be that inbreeding produces a decrease in resistance to pathogens through two possible ways: either by a loss of heterosis at the Major Histocompatibility Complex, which is essential for the immune function of organisms (Edwards and Hedrick, 1998; Hedrick and Kim, 2000), or by 
genome-wide effects either through homozygosity of deleterious recessive alleles or overdominance (e.g. Ferguson and Drahushchak, 1990). Recently, a direct relationship between individual inbreeding coefficients and parasites burden has been portrayed in a subset of the study population of Cuvier's gazelles (Cassinello et al., 2001), but I have no data which relates nematode infections with survival rate in the species. Less heterozygous Soay sheep (Ovis aries) were more susceptible to nematode infections and suffered greater mortality during harsh winters (Coltman et al., 1999).

The onset of sexual activity in the three species of gazelles studied follows the direction mhorr $>$ Cuvier's $>$ dorcas (Table 2), which coincides with their average body size, sexual maturity and life span. This follows the hypothesized direct relationship between reproductive features in mammals and allometry (Millar, 1977; Western and Ssemakula, 1982; Peters, 1983; Calder, 1984). As observed in other mammal species, long life spans correlate with developmental periods (or delayed sexual maturity) (e.g. Western and Ssemakula, 1982; Arking, 1998).

Also, metabolic rate theory suggests that body size correlates with longevity (see Arking, 1998), but this pattern does not seem to fit in the study gazelle species. One possible explanation may lie on ecological factors, i.e., Cuvier's gazelle is a mountain species, that inhabits North African mountain chains (see Escós, 1992); they live in relatively small herds, and although migration, particularly of males, is expected between familiar groups, this species has probably evolved under certain genetic stress and developed some inbreeding tolerance (Bengtsson, 1978; Connor and Bellucci, 1979; Smith, 1979; Waser et al., 1986; see also Alados and Escós, 1991). On 
the contrary, both dorcas and mhorr gazelles are desert ungulates whose natural habitat is the open plains of the Saharan desert, where they form relatively large herds who migrate in search of water and food (Newby, 1984). The probability of groups encounters increases with this life-history and these species would not have evolved under any inbreeding pressure. The captive study populations of the three gazelle species show different average inbreeding coefficients, with Cuvier's possessing higher values but yet enjoying a relatively high longevity rate (see Table 4), perhaps due to its postulated inbreeding tolerance. I would hypothesize that differing inbreeding coefficients in the study populations interferes in the life history variables observed and determines their relationships.

Recent reviews on the effects of inbreeding among different taxa (Crnokrak and Roff, 1999; Hedrick and Kalinowski, 2000; Keller and Waller, 2002) do not question anymore inbreeding depression as a generalized deleterious effect on fitness, caused by the lack of genetic variability; on the contrary, these studies highlight our need to understanding differences according to taxa, environmental conditions and even populations with contrasting demographic and genetic histories. There are several issues to be tackled which offer yet unresolved complex questions, such as comparisons between captive and wild populations of the same species, the postulated higher inbreeding depression under stressful or simply field conditions, and, finally, variations of individual inbreeding deleterious effects within the same population (sex or age-related effects). These are future research lines worth exploring in the near future. 
Kalinowski and Hedrick (1999) have pointed out the difficulties in getting sufficient statistical power to detect inbreeding depression from the analysis of captive populations, so that we should be cautious in getting any conclusions upon apparent inbreeding tolerance or the lack of inbreeding depression from these studies. A deeper knowledge of inbreeding effects on life history traits in endangered species is a must, if we wish to preserve them from their threats and an eventual extinction. In order to carry out fine studies, detailed analyses of well-monitored captive populations will prove great conservation value. I encourage continuing studying the captive ungulates populations hosted at the EEZA (Almería, Spain), including the three gazelle species studied here as well as the other valuable population of aoudads (Ammotragus lervia) breeding there since early 70's (Cassinello, 1998). The study of these captive populations, whose genealogies are so well registered, is helping us in understanding their life histories as well as their behaviour in the wild. All this knowledge is basic if we want to reduce the decline most of their African wild populations are currently suffering.

\section{Acknowledgements}

I would like to thank Mar Cano, Teresa Abaigar and Juan Escós for their work as studbook-keepers at the EEZA during so many years. Thanks to their efforts and the proper management and monitoring of these captive but valuable gazelle populations, along with the professionality of herds keepers and managers, such as Ramón Escamilla, we can nowadays enjoy such a magnificient African legacy in the south of Europe. The manuscript has been substantially improved thanks to comments and suggestions of Teresa Abaigar and two anonymous reviewers. Finally, thanks to 
Alfonso Navas' support and encouragement and for allowing me to use the facilities at the Museo Nacional de Ciencias Naturales (CSIC) during the preparation of the manuscript. The author is currently supported by the Ministerio de Educación y Ciencia through a Ramón y Cajal Contract. 


\section{References}

Abaigar, T., 1993. Gazella dorcas neglecta. International Studbook (1991).

Cuadernos Monográficos, no. 22. Instituto de Estudios Almerienses, Diputación de Almería, Almería.

Abaigar, T., Cano, M., Espeso, G., and Ortiz, J., 1997. Introduction of mhorr gazelle in Bou-Hedma National Park, Tunisia. International Zoo Yearbook 35, 311--316.

Alados, C.L., and Escós, J., 1991. Phenotypic and genetic characteristics affecting lifetime reproductive success in female Cuvier's, dama and dorcas gazelles (Gazella cuvieri, G. dama and G. dorcas). Journal of Zoology, London 223, 307--321.

Alados, C.L., and Escós, J. 1994. Variation in the sex ratio of a low dimorphic polygynous species with high levels of maternal reproductive effort: Cuvier's gazelle. Ethology Ecology and Evolution 6, 301--311.

Arking, R., 1998. Biology of Aging. 2nd edn. Sinauer Associates, Inc., Sunderland, MA.

Ballou J., 1983. Calculating inbreeding coefficients from pedigrees. In Genetics and Conservation: A Reference for Managing Wild Animal and Plant Populations, ed.

C.M. Schonewald-Cox, S.M. Chambers, B. MacBryde and L. Thomas, pp. 509--520. Benjamin/Cummins Publishing Co., London. 
Ballou, J., and Ralls, K., 1982. Inbreeding and juvenile mortality in small populations of ungulates: a detailed analysis. Biological Conservation 24, 239--272.

Ballou, J.D., 1997. Ancestral inbreeding only minimally affects inbreeding depression in mammalian populations. The Journal of Heredity 88, 169--178.

Bengtsson, B.O., 1978. Avoiding inbreeding: at what cost? Journal of theoretical Biology 73, 439--444.

Bright, P.W., and Morris, P.A., 1994. Animal translocation for conservation: performance of dormice in relation to release methods, origin and season. Journal of Applied Ecology 31, 699--708.

Brook, B.W., Tonkyn, D.W., O'Grady, J.J., and Frankham, R., 2002. Contribution of inbreeding to extinction risk in threatened species. Conservation Ecology 6, 16. [online] URL: http://www.consecol.org/vol6/iss1/art16

Brown, J.L., and Brown, E.R., 1998. Are inbred offspring less fit? Survival in a natural population of Mexican jays. Behavioral Ecology 9, 60--63.

Cade, T.J., 1988. Using science and technology to reestablish species lost in nature. In Biodiversity, ed. E.O. Wilson, pp. 279--288. National Academy Press, Washington, D.C. 
Calder, W.A., 1984. Size, Function and Life History. Harvard University Press, Cambridge, MA.

Cano, M., 1991. El Antílope Mohor (Gazella (Nanger) dama mhorr Bennett, 1832) en Cautividad. Tesis Doctoral. Servicio de Publicaciones de la Universidad de Granada, Granada.

Cano, M., Abaigar, T., and Vericad, J.R., 1993. Establishment of a group of dama gazelles (Gazella (=Nanger) dama) for reintroduction in Senegal. International Zoo Yearbook 32, 98--107.

Carbyn, L.N., Armbruster, H.J., and Mamo, C., 1993. The swift fox reintroduction program in Canada from 1983 to 1992. In Restoration of Endangered Species, eds. M.L. Bowles and C.J. Whelan, pp. 247--271. Cambridge University Press, Cambridge.

Cassinello, J., 1997. High levels of inbreeding in captive Ammotragus lervia (Bovidae, Artiodactyla): Effects on phenotypic variables. Canadian Journal of Zoology 75, 1707--1713.

Cassinello, J., 1998. Ammotragus lervia: a review on systematics, biology, ecology and distribution. Annales Zoologici Fennici 35, 149--162 
Cassinello, J., Abaigar, T., Gomendio, M., and Roldan, E.R.S., 1998. Characteristics of the ejaculate in three endangered species of gazelles (Gazella dama mhorr, G. dorcas neglecta and G. cuvieri). Journal of Reproduction and Fertility 113, 35--45.

Cassinello, J. and Alados, C.L. 1996. Female reproductive success in captive Ammotragus lervia (Bovidae, Artiodactyla). Study of its components and effects of hierarchy and inbreeding. Journal of Zoology, London 239, 141--153.

Cassinello, J. and Gomendio, M., 1996. Adaptive variation in litter size and sex ratio at birth in a sexually dimorphic ungulate. Proceedings of the Royal Society of London, Series B 263, 1461-1466.

Cassinello, J., Gomendio, M., and Roldan, E.R.S., 2001. The relationship between coefficient of inbreeding and parasite burden in endangered gazelles. Conservation Biology 15, 1171--1174.

Cassinello, J., and Pieters, I., 2000. Multi-male captive groups of endangered dama gazelle: social rank, aggression, and enclosure effects. Zoo Biology 19, 121--129.

Charlesworth, D., and Charlesworth, B., 1987. Inbreeding depression and its evolutionary consequences. Annual Review of Ecology and Systematics 18, 237--268.

Clutton-Brock, T.H., ed., 1988. Reproductive Success. The University of Chicago Press, Chicago. 
Coltman, D. W., Pilkington, J.G., Smith, J.A., and Pemberton, J.M., 1999. Parasitemediated selection against inbred Soay sheep in a free-living, island population. Evolution 53, 1259--1267.

Connor, J.L., and Bellucci, M.J., 1979. Natural selection resisting inbreeding depression in captive wild house mice (Mus musculus). Evolution 33, 929--940.

Crnokrak, P., and Roff, D.A., 1999. Inbreeding depression in the wild. Heredity 83, 260--270.

Edwards, S., and Hedrick, P.W., 1998. Evolution and ecology of MHC molecules: from genomics to sexual selection. Trends in Ecology and Evolution 13, 305-311.

Escós, J., 1992. Gazella cuvieri. International Studbook (1990). Cuadernos Monográficos, no. 20. Instituto de Estudios Almerienses, Diputación de Almería, Almería.

Falconer, D.S., and MacKay, T.F.C., 1996. Introduction to Quantitative Genetics. 4th edn. Longman Scientific and Technical, Burnt Mill, Harlow, United Kingdom.

Ferguson, M.M., and Drahushchak, L.R., 1990. Disease resistance and enzyme heterozygosity in rainbow trout. Heredity 64, 413--417.

Foose, T.J., and Ballou, J.D., 1988. Population management: theory and practice. International Zoo Yearbook 27, 26--41. 
Frankel, O.H. \& Soulé, M.E. 1981. Conservation and Evolution. Cambridge University Press, Cambridge.

Frankham, R. 1995a. Effective population size/adult population size ratios in wildlife: a review. Genetical Research 66, 95--107.

Frankham, R 1995b. Conservation genetics. Annual Review of Genetics 29, 305--327.

Frankham, R 1995c. Inbreeding and extinction: A threshold effect. Conservation Biology 9, 792--799.

Gomendio, M., Cassinello, J., and Roldan, E.R.S., 2000. A comparative study of ejaculate traits in three endangered ungulates with different levels of inbreeding: Fluctuating asymmetry as an indicator of reproductive and genetic stress. Proceedings of the Royal Society of London, Series B 267, 875-882.

Gompper, M.E., Stacey, P.B., and Berger, J., 1997. Conservation implications of the natural loss of lineages in wild mammals and birds. Conservation Biology 11, 857-867.

Grant, P.R., Grant, B.R., and Petren, K., 2001. A population founded by a single pair of individuals: establishment, expansion and evolution. Genetica 112/113, 359--382. 
Griffith, B., Scott, J.M., Carpenter, J.W., and Reed, C., 1989. Translocations as a species conservation tool: status and strategy. Science $245,477--480$.

Harcourt, A.H., 1987. Dominance and fertility among female primates. Journal of Zoology, London 213, 471--487.

Hass, C.C., 1989. Bighorn lamb mortality: predation, inbreeding, and population effects. Canadian Journal of Zoology 67, 699--705.

Hedrick, P.W., and Kalinowski, S.T., 2000. Inbreeding depression in conservation biology. Annual Review of Ecology and Systematics 31, 139--162.

Hedrick, P.W., and Kim, K.J., 2000. Genetics of complex polymorphisms: Pathogens and maintenance of the major histocompatibility complex variation. In Evolutionary Genetics: From Molecules to Morphology, ed. R.S. Singh and C.B. Krimbas, pp. 204-234. Cambridge University Press, Cambridge.

IUCN, 2002. 2002 IUCN Red List of Threatened Species. <www.redlist.org>. Downloaded on 7 September 2003.

Kalinowski, S.T., and Hedrick, P.W., 1999. Detecting inbreeding depression is difficult in captive endangered species. Animal Conservation 2, 131--136.

Keller, L.F., 1998. Inbreeding and its fitness effects in an insular population of song sparrows (Melospiza melodia). Evolution 52, 240--250. 
Keller, L.F., and Waller, D.M., 2002. Inbreeding effects in wild populations. Trends in Ecology and Evolution 17, 230--241.

Kleiman, D.G., Beck, B.B., Dietz, J.M., Dietz, L.A., Ballou, J.D., and Coimbra-Filho, A.F., 1986. Conservation program for the golden lion tamarin: captive research and management, ecological studies, educational strategies, and reintroduction. In Primates: The Road to Self-sustaining Populations, ed. K. Benirschke, pp. 959--980. Springer-Verlag, New York.

Komers, P.E., and Curman, G.P., 2000. The effect of demographic characteristics on the success of ungulate re-introductions. Biological Conservation 93, 187--193.

Kromrey, J.D., and La Rocca, M.A., 1995. Power and Type I error rates of new pairwise multiple comparison procedures under heterogeneous variances. Journal of Experimental Education 63, 343--362.

Kruuk, L.E.B., Slate, J., Pemberton, J.M., and Clutton-Brock, T.H., 2003. Fluctuating asymmetry in a secondary sexual trait: no associations with individual fitness, environmental stress or inbreeding, and no heritability. Journal of Evolutionary Biology 16, 101--113.

Lacy, R.C., Alaks, G., and Walsh, A., 1996. Hierarchical analysis of inbreeding depression in Peromyscus polionotus. Evolution 50, 2187--2200. 
MacNeil, M.D., Dearborn, D.D., Cundiff, L.V., Dinkel, C.A., and Gregory, K.E., 1989. Effect of inbreeding and heterosis in Hereford females on fertility, calf survival and preweaning growth. Journal of Animal Science 67, 895--901.

Millar, J.S., 1977. Adaptive features of mammalian reproduction. Evolution 31, 370--386.

Mills, L.S., and Smouse, P.E., 1994. Demographic consequences of inbreeding in remnant populations. The American Naturalist 144, 412--431.

Newby, J.E., 1984. Large mammals. In Sahara Desert, ed. J.L. Cloudsley-Thompson, pp. 177--190. Pergamon Press, Oxford.

Perneger, T.V., 1998. What is wrong with Bonferroni adjustments. British Medical Journal 136, 1236--1238.

Peters, R.H., 1983. The Ecological Implications of Body Size. Cambridge University Press, Cambridge.

Promislow, D.E.L., 1992. Costs of sexual selection in natural populations of Mammals. Proceedings of the Royal Society of London, Series B 247, 203--210.

Rahbeck, C., 1993. Captive breeding - A useful tool in the preservation of biodiversity? Biodiversity and Conservation 2, 426--437. 
Ralls, K., Brugger, K., and Ballou, J., 1979. Inbreeding and juvenile mortality in small populations of ungulates. Science 206, 1101--1103.

Reed, D.H., Briscoe, D.A., and Frankham, R., 2002. Inbreeding and extinction: The effect of environmental stress and lineage. Conservation Genetics 3, 301--307.

Reed, D.H., Lowe, E.H., Briscoe, D.A., and Frankham, R., 2003. Inbreeding and extinction: Effects of rate of inbreeding. Conservation Genetics 4, 405--410.

Ryder, O.A., 1987. Conservation action for gazelles: an urgent need. Trends in Ecology and Evolution 2, 143--144.

Saccheri, I., Kuussaari, M., Kankare, M., Vikman, P., Fortelius, W., and Hanski, I., 1998. Inbreeding and extinction in a butterfly metapopulation. Nature 392, 491--494.

Slate, J., Kruuk, L.E.B., Marshall, T.C., Pemberton, J.M., and Clutton-Brock, T.H., 2000. Inbreeding depression influences lifetime breeding success in a wild population of red deer. Proceedings of the Royal Society of London, Series B 267, 1657--1662.

Smith, R.H., 1979. On selection for inbreeding in polygynous animals. Heredity 43, 205--211.

Snyder, N.F.R., Derrickson, S.R., Beissinger, S.R.,Wiley, J.W., Smith, T.B., Toone, W.D., and Miller, B., 1996. Limitations of captive breeding in endangered species recovery. Conservation Biology 10, 338--348. 
Stanley Price, M.R., 1989. Animal Re-introductions: The Arabian Oryx in Oman. Cambridge University Press, Cambridge.

Stockley, P., Searle, J.B., MacDonald, D.W., and Jones, C.S., 1993. Female multiple mating behaviour in the common shrew as a strategy to reduce inbreeding. Proceedings of the Royal Society of London, Series B 254, 173--179.

Thornhill, N.W., ed., 1993 The Natural History of Inbreeding and Outbreeding. The University of Chicago Press, Chicago.

Toïgo, C., and Gaillard, J.-M., 2003. Causes of sex-biased adult survival in ungulates: sexual size dimorphism, mating tactic or environment harshness? Oikos 101, 376-384.

van Noordwijk, A.J., and Scharloo, W., 1981. Inbreeding in an island population of the great tit. Evolution 35, 674--688.

Waser, P.M., Austad, S.N., and Keane, B., 1986. When should animals tolerate inbreeding? The American Naturalist 128, 529--537.

Watson, J., Warman, C., Todd, D., and Laboudallon, V., 1992. The Seychelles magpie robin Copsychus sechellarum: ecology and conservation of an endangered species. Biological Conservation 61, 93--106. 
Western, D., and Ssemakula, J., 1982. Life history patterns in birds and mammals and their evolutionary interpretation. Oecologia 54, 281-290.

Wielebnowski, N., 1996. Reassessing the relationship between juvenile mortality and genetic monomorphism in captive cheetahs. Zoo Biology 15, 353--369.

Wright, S., 1922. Coefficients of inbreeding and relationship. The American Naturalist 56, 330--338.

Wright, S., 1977. Evolution and the Genetics of Populations. Vol. 3. Experimental Results and Evolutionary Deductions. The University of Chicago Press, Chicago.

Zar, J.H., 1984. Biostatistical Analysis. 2nd ed. Prentice-Hall, Inc., Englewood Cliffs, New Jersey. 


\section{Figure legends}

Figure 1. Relative frequencies of parturition types in Cuvier's gazelles.

Figure 2. Relationship between inbreeding coefficient and longevity (both logtransformed) for dorcas males (a) and females (b), Cuvier's males (c) and females (d), and mhorr males (e) and females (f). Regression equation, sample size and probability are shown for each analysis. 
Table 1. Founding individuals sex ratio (males:females), effective population size $\left(\mathrm{N}_{\mathrm{e}}=(4 \times\right.$ no.males $\mathrm{x}$ no.females $) /($ no.males + no.females $\left.)\right)$, proportion of genetic variation remaining in the population per generation $\left(1-1 /\left(2 \mathrm{~N}_{\mathrm{e}}\right)\right)$, and inbreeding coefficients in the three captive populations of gazelles present at the EEZA. Sample size is shown in parenthesis. The median of the inbreeding coefficients refers exclusively to those individuals whose longevity is known (see 'Inbreeding coefficients' section in the Methods).

\begin{tabular}{|l|l|l|l|}
\hline & dorcas gazelle & Cuvier's gazelle & mhorr gazelle \\
\hline \hline Founding sex ratio & $11: 13$ & $2: 2$ & $3: 9$ \\
\hline $\mathrm{N}_{\mathrm{e}}$ & 24 & 4 & 9 \\
\hline $1-1 /\left(2 \mathrm{~N}_{\mathrm{e}}\right)$ & 0.98 & 0.87 & 0.94 \\
\hline$F$ mean \pm S.E. & $0.051 \pm 0.003(758)$ & $0.166 \pm 0.005(413)$ & $0.115 \pm 0.004(509)$ \\
\hline$F$ range & $0.000-0.381$ & $0.000-0.428$ & $0.000-0.391$ \\
\hline$F$ median & 0.000 & 0.1875 & 0.1250 \\
\hline
\end{tabular}


Table 2. Sexual maturity age for males and females, gestation duration, and average age at first birth, for dorcas, Cuvier's and mhorr study populations. Data obtained from the studbook database except when otherwise indicated. Sample size is shown in parenthesis.

\begin{tabular}{|l|l|l|l|}
\hline Reproductive trait & dorcas gazelle & Cuvier's gazelle & mhorr gazelle \\
\hline \hline Sexual maturity age & & & \\
Males & 9 months & 13 months & 14 months \\
Females & 5 months & 7 months & 8 months \\
\hline Gestation & 5.63 months $^{1}$ & 5.37 months $^{2}$ & 6.67 months $^{3}$ \\
\hline Average age at first birth & 1.99 years $(112)$ & 2.18 years $(99)$ & 2.20 years $(90)$ \\
\hline
\end{tabular}

${ }^{1}$ Abaigar, 1993; ${ }^{2}$ Escós, 1992; ${ }^{3}$ Cano, 1991 
Table 3. Counts of parturition types according to maternal experience in the three study populations of gazelles. Note that only Cuvier's gazelles give birth to twins. Primip $=$ primiparous, Multip $=$ multiparous .

\begin{tabular}{|c|c|c|c|c|c|c|}
\hline Types of parturition & \multicolumn{2}{|c|}{ dorcas gazelle } & \multicolumn{2}{|c|}{ Cuvier's gazelle } & \multicolumn{2}{|c|}{ mhorr gazelle } \\
\hline & Primip & Multip & Primip & Multip & Primip & Multip \\
\hline Males & 69 & 236 & 22 & 43 & 51 & 189 \\
\hline Females & 66 & 235 & 31 & 43 & 50 & 188 \\
\hline Males/Males & - & - & 8 & 22 & - & - \\
\hline Males/Females & - & - & 11 & 31 & - & - \\
\hline Females/Females & - & - & 7 & 21 & - & - \\
\hline
\end{tabular}


Table 4. Average longevity in years $( \pm$ S.E.) of non-inbred males and females of the three gazelle species studied. Sample size is shown in parenthesis.

\begin{tabular}{|c|c|c|c|c|c|c|}
\hline & dorcas & gazelle & Cuvier's & azelle & mhorr & gazelle \\
\hline Sex & $\begin{array}{l}\text { males } \\
\text { (168) }\end{array}$ & $\begin{array}{c}\text { females } \\
\text { (129) }\end{array}$ & $\begin{array}{c}\text { males } \\
(6)\end{array}$ & $\begin{array}{c}\text { females } \\
\text { (13) }\end{array}$ & $\begin{array}{l}\text { males } \\
(34)\end{array}$ & $\begin{array}{c}\text { females } \\
(41)\end{array}$ \\
\hline Average longevity & $1.39 \pm 0.15$ & $2.22 \pm 0.27$ & $5.61 \pm 1.35$ & $5.03 \pm 1.05$ & $1.84 \pm 0.44$ & $4.15 \pm 0.82$ \\
\hline Range & $0.00-9.25$ & $0.00-14.82$ & $2.07-10.50$ & $0.00-12.91$ & $0.00-9.97$ & $0.00-15.89$ \\
\hline
\end{tabular}


Table 5. Percentage of non-inbred and inbred males and females that reaches one month and sexual maturity age in the three study gazelle populations. Number of cases are shown in parenthesis. Bonferroni correction applied.

\begin{tabular}{|c|c|c|c|c|c|c|}
\hline MALES & dorcas & gazelle & Cuvier's & gazelle & \multicolumn{2}{|c|}{ mhorr gazelle } \\
\hline Inbreeding group & Non-inbred & Inbred & Non-inbred & Inbred & Non-inbred & Inbred \\
\hline One month survival & $80 \%(184)$ & $71 \%(110)$ & $100 \%(22)^{1}$ & $73 \%(136)^{1}$ & $74 \%(37)$ & $68 \%(138)$ \\
\hline Sexual maturity survival & $58 \%(134)^{6}$ & $55 \%(85)$ & $100 \%(22)^{3}$ & $62 \%(115)^{3}$ & $58 \%(29)^{7}$ & $47 \%(90)$ \\
\hline FEMALES & Dorcas & gazelle & Cuvier's & gazelle & Mhor & gazelle \\
\hline Inbreeding group & Non-inbred & Inbred & Non-inbred & Inbred & Non-inbred & Inbred \\
\hline One month survival & $81 \%(167)$ & $76 \%(101)$ & $96 \%(28)$ & $79 \%(106)$ & $85 \%(65)^{2}$ & $68 \%(122)^{2}$ \\
\hline Sexual maturity survival & $72 \%(148)^{6}$ & $62 \%(83)$ & $93 \%(27)^{4}$ & $68 \%(91)^{4}$ & $79 \%(60)^{5,7}$ & $58 \%(100)^{5}$ \\
\hline
\end{tabular}

Significant differences between low and high-inbred individuals (Contingency 2-way table tests):

${ }^{1} d f=1$, Fisher's Exact $p$ value $=0.003$

${ }^{2} d f=1, \chi^{2}=7.91, p=0.005$

${ }^{3} d f=1$, Fisher's Exact $p$ value $<0.0001$

${ }^{4} d f=1$, Fisher's Exact $p$ value $=0.005$

${ }^{5} d f=1, \chi^{2}=10.28, p=0.001$

Significant differences between males and females (Contingency 2 -way table tests):

${ }^{6} d f=1, \chi^{2}=8.89, p=0.003$

${ }^{7} d f=1, \chi^{2}=6.38, p=0.01$ 
Table 6. Percentage of males and females dead in the study population of mhc gazelles, according to eight different causes (see Methods for definitions). No and inbred individuals are distinguished. Sample size is shown in parenthesis. Bonferroni correction applied.

\begin{tabular}{|c|c|c|c|c|}
\hline Inbreeding class & Inbreeding & $=0$ & Inbreeding & $>0$ \\
\hline Sex & males (37) & females (53) & males (126) & females \\
\hline Pathology & $22 \%(8)^{1,2}$ & $62 \%(33)^{1,3}$ & $51 \%(64)^{2,4,5}$ & $56 \% 1$ \\
\hline Traumatism & $35 \%(13)$ & $19 \%(10)$ & $20 \%(25)^{4}$ & $25 \%$ \\
\hline Non-nursed & $3 \%(1)$ & $4 \%(2)^{3}$ & $9 \%(11)^{5}$ & $8 \% 1$ \\
\hline Born dead & $5 \%(2)$ & $4 \%(2)^{3}$ & $7 \%(9)^{5}$ & $7 \% 1$ \\
\hline Herdmate aggression & $16 \%(6)$ & $2 \%(1)^{3}$ & $5 \%(6)^{5}$ & $4 \% 1$ \\
\hline Sacrified & $11 \%(4)$ & $2 \%(1)^{3}$ & $7 \%(9)^{5}$ & $0 \%($ \\
\hline Motherless & $8 \%(3)$ & $2 \%(1)^{3}$ & $2 \%(2)^{5}$ & $0 \%($ \\
\hline Post-partum death & - & $6 \%(3)^{3}$ & - & $0 \%($ \\
\hline
\end{tabular}

Significant differences between males and females (Contingency 2-way table tests): ${ }^{1} d f=1, \chi^{2}=14.51, p=0.0001$

Significant differences between non-inbred and inbred individuals (Contingency 2-way table ${ }^{2} d f=1, \chi^{2}=9.87, p=0.002$

Significant differences between causes of death (Contingency 2-way table tests):

${ }^{3} d f=1$, Fisher's Exact $p$ value $\leq 0.0002$ (pathology vs. the other causes) ${ }^{4} d f=1, \chi^{2}=8.93, p=0.003$

${ }^{5} d f=1$, Fisher's Exact $p$ value $<0.0001$ (pathology vs. the other causes) ${ }^{6} d f=1$, Fisher's Exact $p$ value $<0.0001$ (pathology vs. the other causes) 
Table 7. Analysis of variance carried out for the dependent variable longevity (transformed into its logarithmic to conform to normality) in the study gazelle populations. The fixed factors are sex, species and median-inbreeding (see Methods).

\begin{tabular}{|l|l|l|l|}
\hline & $d f$ & $F$ value & $p$ value \\
\hline Sex & 1 & 8.134 & 0.005 \\
\hline Species & 2 & 2.286 & 0.10 \\
\hline Median-inbreeding & 1 & 21.687 & $<0.0001$ \\
\hline Sex * Species & 2 & 0.223 & 0.80 \\
\hline Sex * Median-inbreeding & 1 & 3.050 & 0.08 \\
\hline Species * Median-inbreeding & 2 & 1.981 & 0.14 \\
\hline Sex * Species * Median-inbreeding & 2 & 0.298 & 0.74 \\
\hline Residual & 1037 & & \\
\hline
\end{tabular}




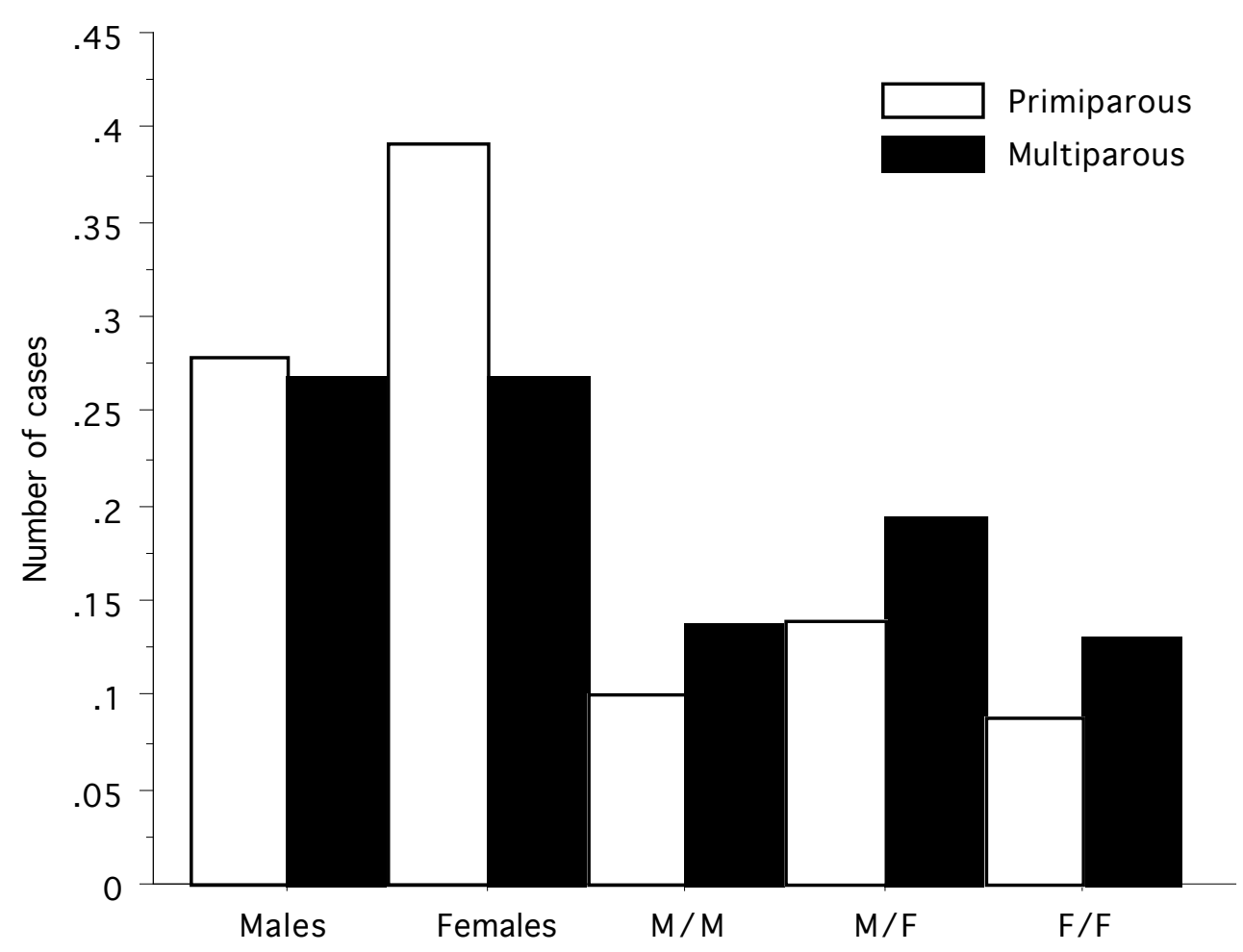

Types of parturition

FIGURE 1 


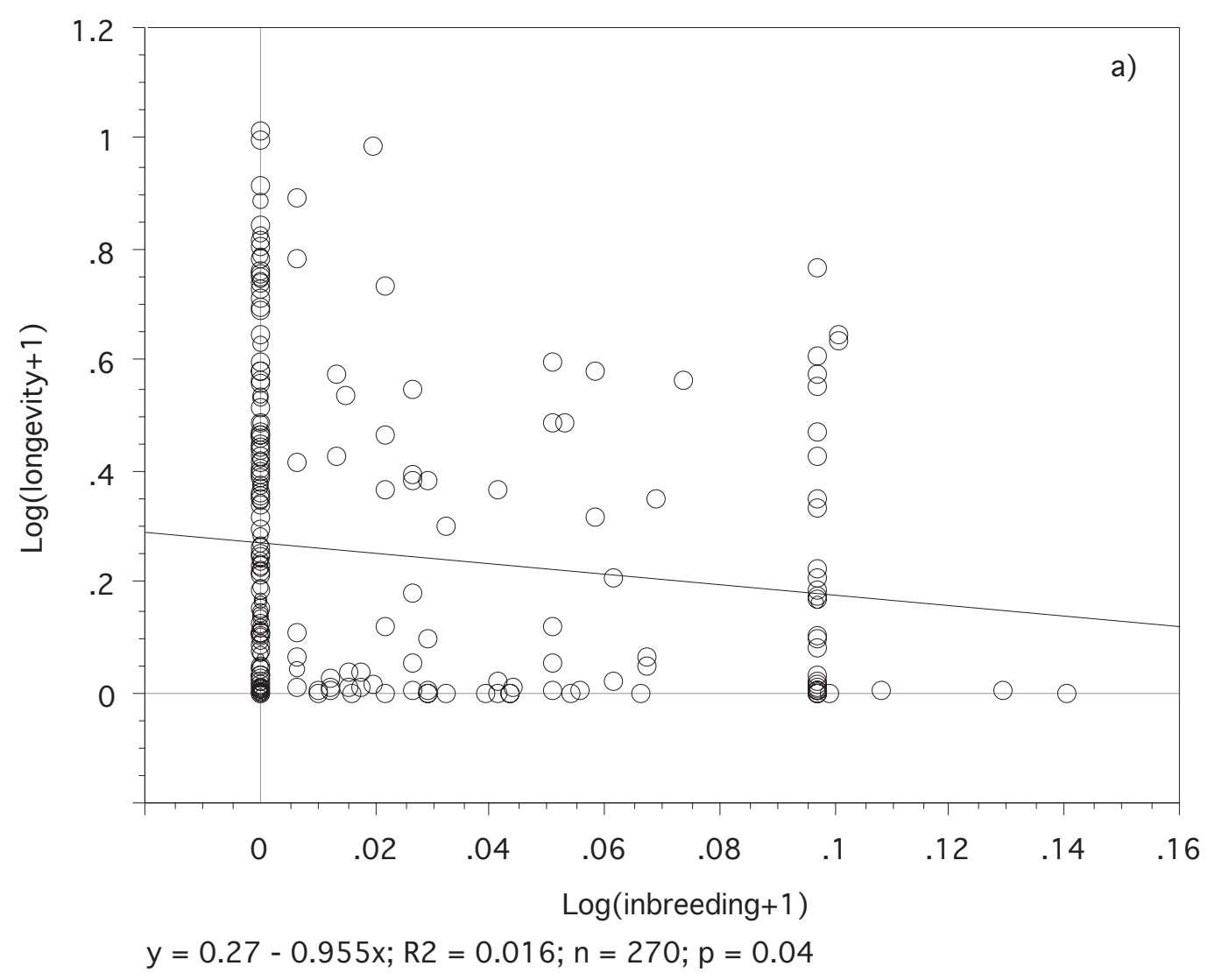

FIGURE 2a 


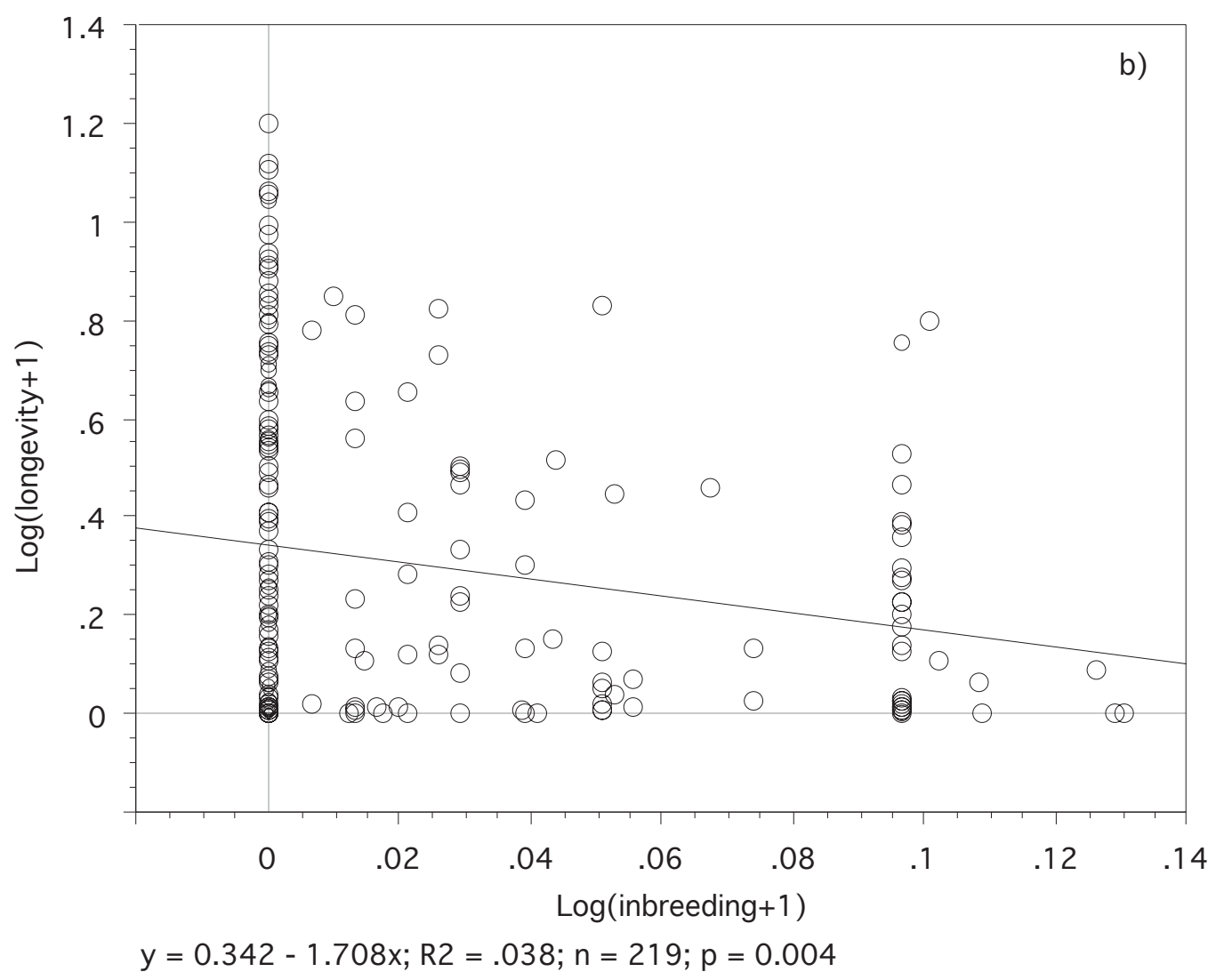

FIGURE 2b 


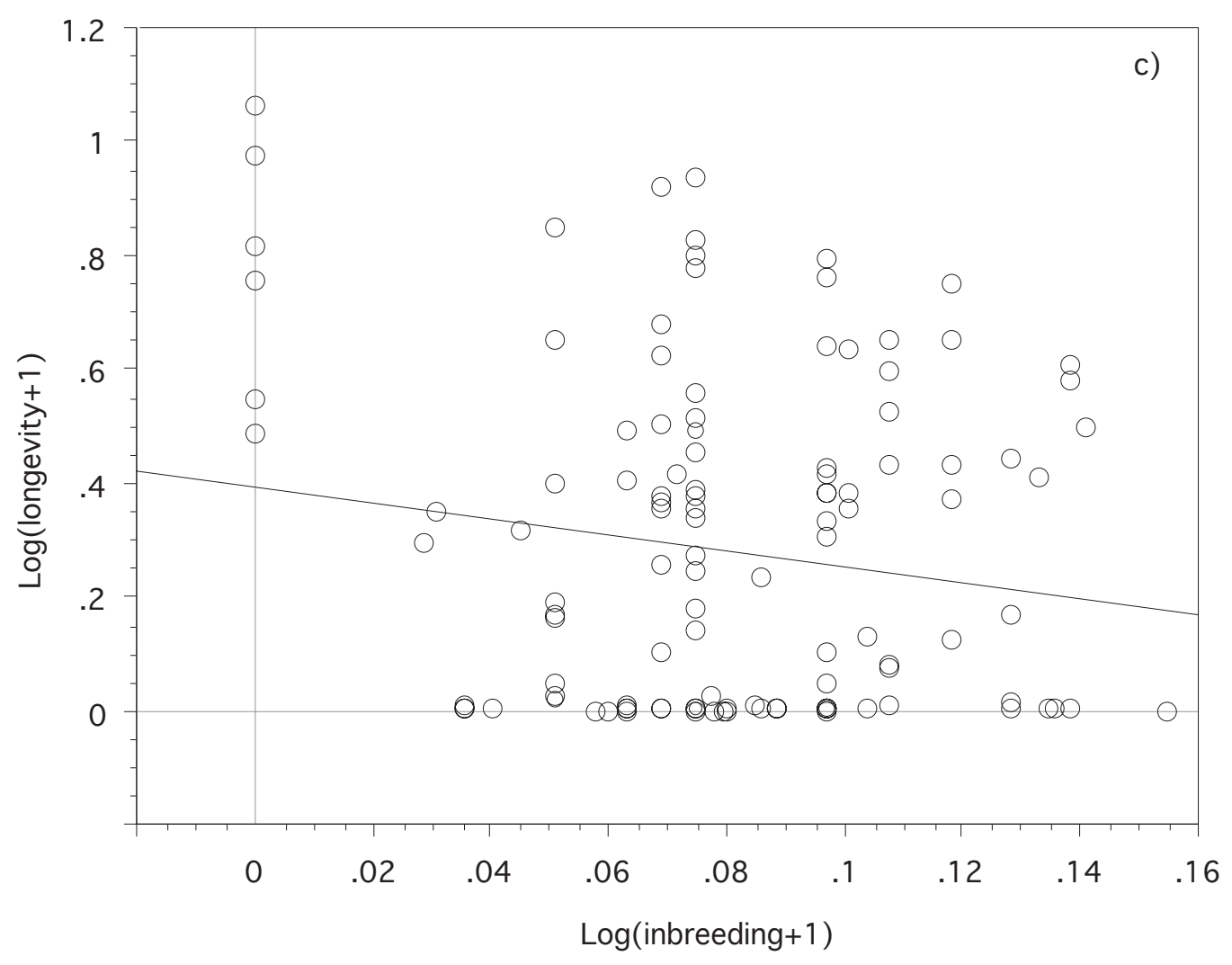

$y=0.394-1.418 x ; R 2=0.024 ; n=127 ; p=0.08$

FIGURE 2c 


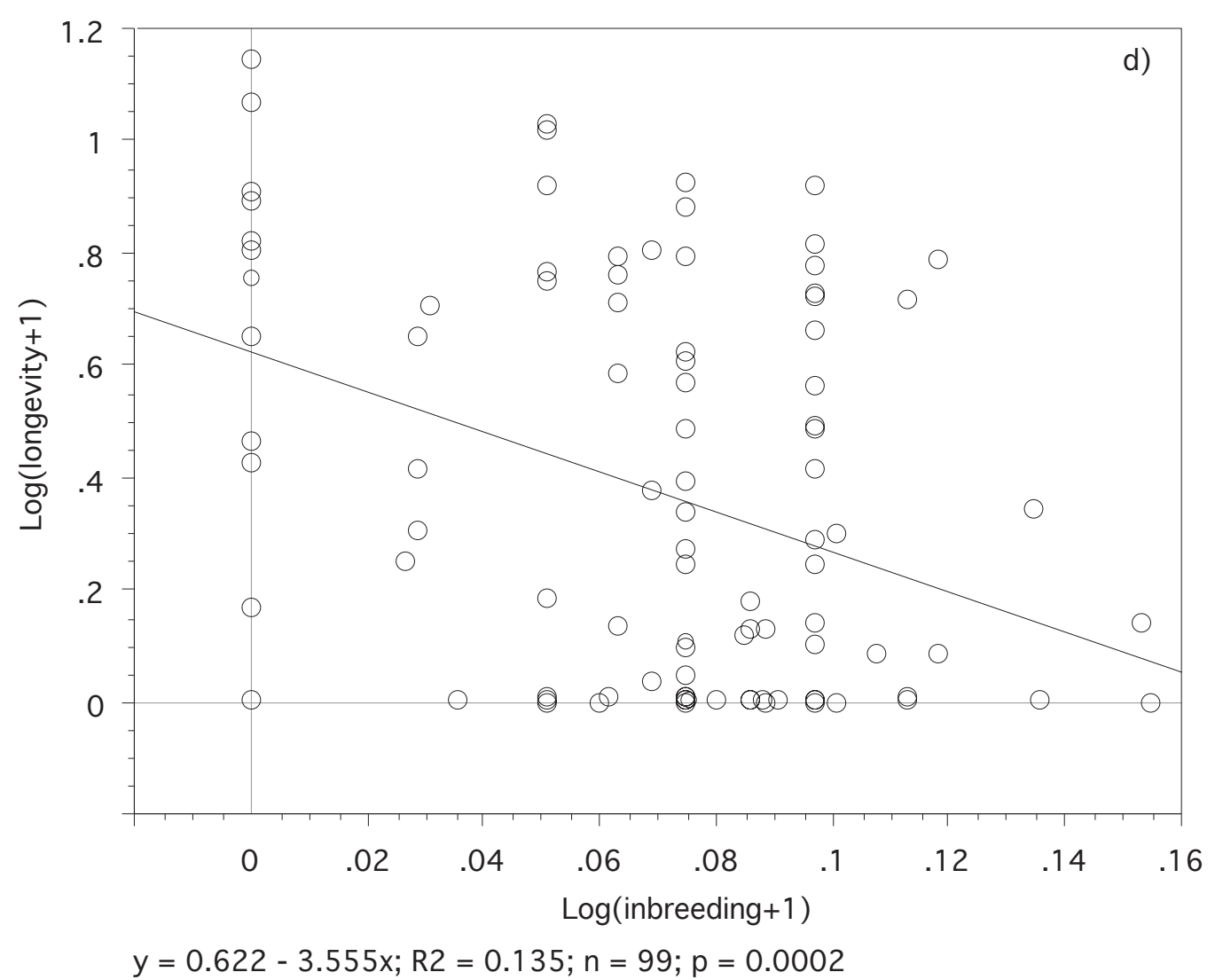

FIGURE 2d 


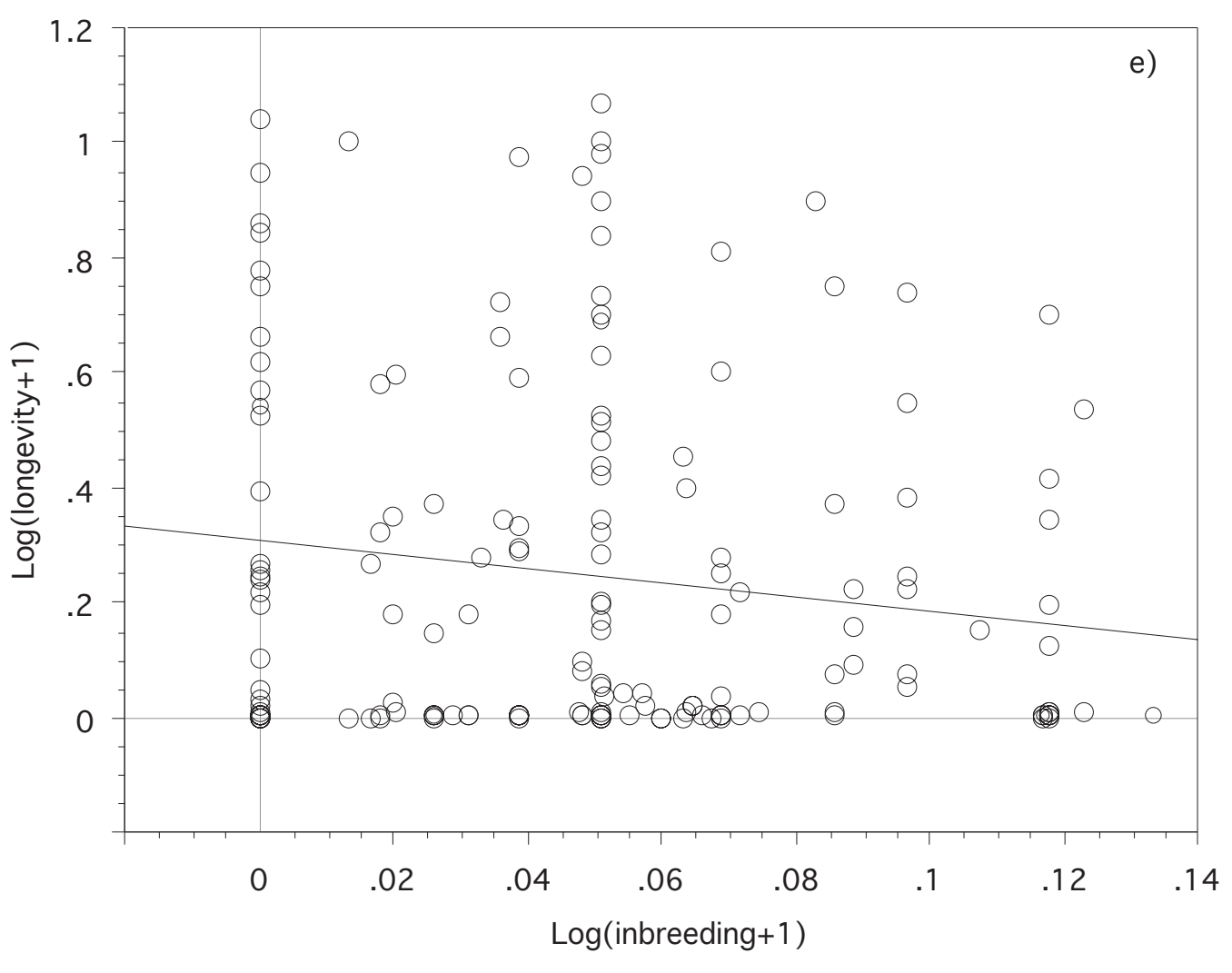

$y=0.306-1.206 x ; R 2=0.022 ; n=178, p=0.05$

\section{FIGURE 2e}




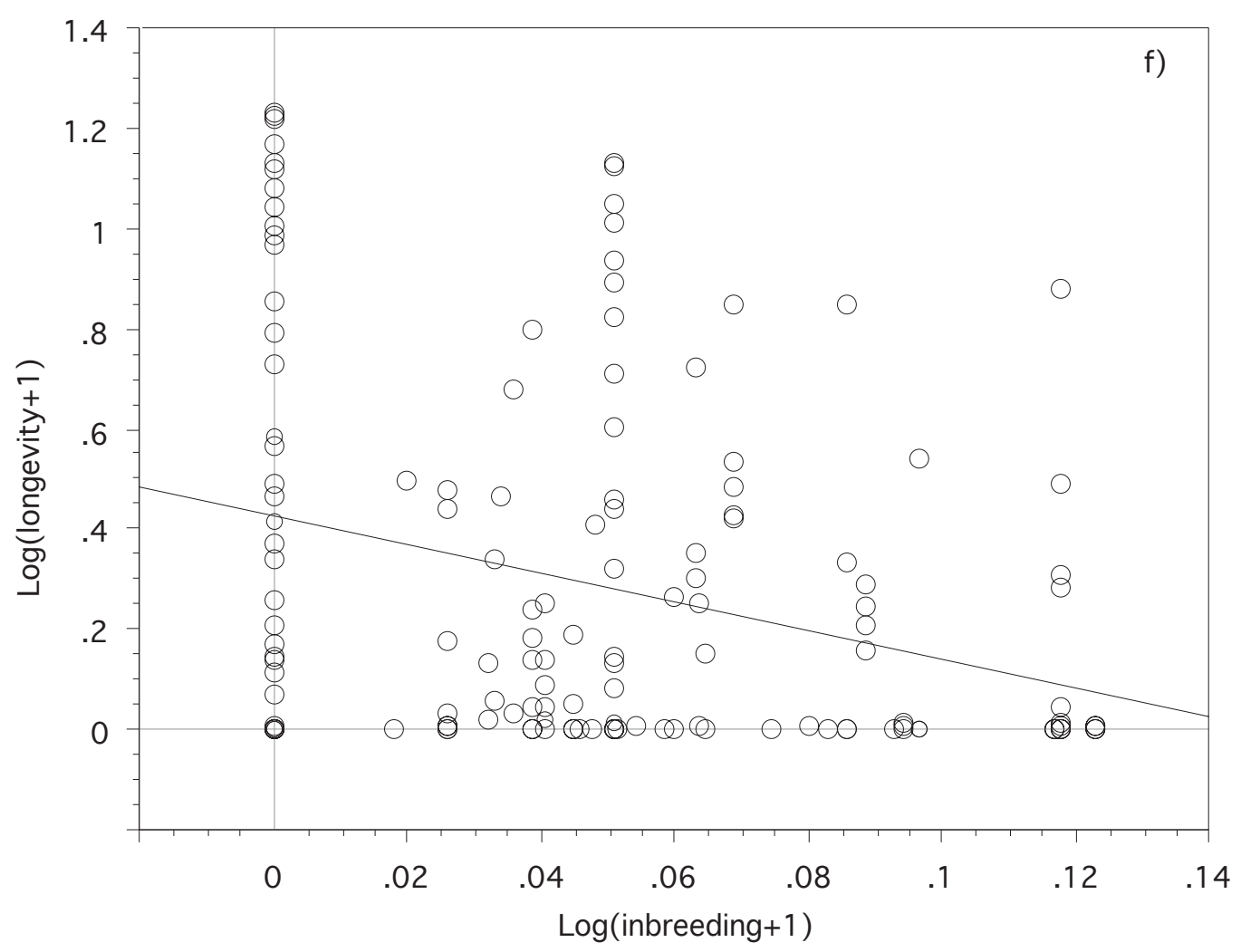

$y=0.425-2.83 x ; R 2=0.089 ; n=156 ; p=0.0002$

FIGURE 2f 